\title{
Roadmap for Implementing Third Mission University
}

\author{
Milly Perry ${ }^{1}$ \\ ${ }^{1}$ The Open University of Israel, Raanana, Israel \\ Correspondence: Dr. Milly Perry, The Open University of Israel, Raanana, Israel. E-mail: millype@openu.ac.il
}

Received: June 25, 2014

Accepted: August 19, 2014

Online Published: August 30, 2014

doi:10.5430/rwe.v5n2p169

URL: http://dx.doi.org/10.5430/rwe.v5n2p169

\begin{abstract}
There is widespread recognition of the growing importance of universities in a knowledge society and a competitive economy, and of their required role in stimulating growth through University-Industry-Government interaction. As Tadmor (2003, p.22) put it "[universities] can show the way, offer the solutions and produce the hardware to resolve the most crucial problems". While the education and research missions of universities have formalized by the universities, their third mission "Technology Transfer" have been recognized and often accepted, but has not been implemented in formalized structures, systems, skills, values and ways of working.
\end{abstract}

Keywords: technology transfer, research triangle, university

\section{Introduction and Theoretical Background}

Many explanations and interpretations have been given in the literature for the astonishing fact that, for decades, there have been no real changes in the way universities act and function. Universities were useful to society but not critical, they served the elite without threatening it, and they were able to respond to popular demands and political needs. Furthermore, they contributed to national economic growth and security (Tadmor, 2003).

Today, changes in circumstance and conditions have driven the universities to change not only the way they act but the way they think. Academic research has become valuable to a nation's progress and competitiveness. At the same time it has become too expensive, and this fact has driven public debate about universities' governance and efficiency. Society's needs for well educated personnel in a vast variety of fields invites close discourse between society as the "end user" and the academic world, which requires the right influence in the process. The globalization of the education world, its promise for business, and the role of university education is increasingly becoming the main tool for social and economic mobility, are other reasons for political intervention and for growing demands for changes in universities and the academic world.

\subsection{The Challenge}

Most of the research that has been carried out in technology transfer and Third Mission University (TMU) emphasizes the need to implement and drive an effective technology transfer process as a return on public investment into the university system. The research looks for responses to "WH" questions. "Why" should the university develop these activities? "When" and "where" should the university develop them? "Who" are the right people to take part in these activities? "What" are the constructive ways to engage them in it? Some research studies suggest practical advice and best practice, others underline specific lenses through which they build a systematic framework dealing with the organizational aspects within the university, environmental aspects (outside of the university) or individual aspects of the required vision. Even though much of the research mentions the change process as the main objective (the vision is widely acknowledged), none of them use Change Management theory as the analysis framework or use Change Management tools for challenging the phenomenon that is clearly recognized as organizational change or the institution's cultural change. Change Management (Nickols, 2004) is defined as handling planned and systematic changes. The purpose of change management is to efficiently assimilate changes and systems into the organization. Change may be perceived to come from within the organization and thus is controlled by it, or it may be understood as a mechanism that responds to shifts that occur in the organization's environment and are not under its control.

The study importance and objectives are, as one of the studies in the literature review put it: "Our understanding of academic institutions from an organizational perspective is quite limited. A fairly large number of publications on the university system have contributed mainly to the identification of different factors in the system's black box [...] few 
pioneering studies have moved further in their attempt to reveal what resides inside the black box, and identify university organizational designs as a key construct of interest" (Rothaermal, Agung and Jiang, 2006).

\subsection{Research Problem}

Most of the research that has been carried out in technology transfer and TMU emphasizes the need to implement and drive an effective technology transfer process as a return on public investment into the university system (Tadmor, 2003). The research looks for responses to "WH" questions. "Why" should the university develop these activities? "When" and "where" should the university develop them? "Who" are the right people to take part in these activities? "What" are the constructive ways to engage them in it? Some research studies suggest practical advice and best practice, others underline specific lenses through which they build a systematic framework dealing with the organizational aspects within the university, environmental aspects (outside of the university) or individual aspects of the required vision. Even though much of the research mentions the change process as the main objective (the vision is widely acknowledged), none of them use Change Management theory as the analysis framework or use Change Management tools for challenging the phenomenon that is clearly recognized as organizational change or the institution's cultural change (Hatakenaka, 2005). Few research studies relate to the barriers for changes, as well as to individual changes. As has been pointed out "most studies [...] offer less on the how and the why", "there is a need to move toward embracing an economic development mandate eliminating the barriers within innovation systems requires further studies of how to effectively facilitate the technology transfer process and what the key resources and capabilities that reduce these barriers are" and "There is no smooth path for any paradigm change" (Rothaermal, Agung and Jiang, 2006 p. 15, 17). The research mentions that "as the scope of an entrepreneurial university expands, the core of the system self-organizes in order to renew and transform its mission" (Rothaermal, Agung and Jiang, 2006, p.8) but does not give any indication as to the way to achieve these goals. Other research reinforces this notion "There has been little empirical scholarship examining the issue of barriers to knowledge transfer in academia" (Jacobson, Butterill \& Goering, 2004, p.248).

Another aspect of the research gap is research about TMU policy, and technology transfer in countries outside the U.S.A and Europe. In Israel there is a long and successful tradition of technology transfer that has not been widely reported. "Although the field is quite international, most studies to date focus on university entrepreneurship in the U.S. and selected European countries. Only a few studies compare or contrast university commercialization activities across countries". (Rothaermal, Agung and Jiang, 2006.p.30) The Israeli experience can be useful for other countries as well.

\subsection{Research Importance and Objectives}

In this research we draft a detailed roadmap for implementing the "Third Mission University" in the Israeli academic system. This roadmap is drawn from successful policies and experiences around the world, taking into consideration Israeli culture and the diversity of universities nature and needs. One of the studies in the literature review put it as follows: "Our understanding of academic institutions from an organizational perspective is quite limited. A fairly large number of publications on the university system have contributed mainly to the identification of different factors in the system's black box [...] few pioneering studies have moved further in their attempt to reveal what resides inside the black box, and identify university organizational designs as a key construct of interest" (Rothaermal, Agung and Jiang, 2006).

The underlying assumption of this study is that there is no universal fit-for-all solution for implementing the TMU. We need to find the right way to meet the cultural differences and regional conditions to articulate a good-enough roadmap for implementing and managing the change. This study will observe and analyze processes around the world to develop the Israeli appropriate roadmap, utilizing a set of indicators with which one can measure the progress towards the goal of implementing the "Third Mission University".

\section{Methodology}

\subsection{Research Questions}

The study begins by considering broader questions, such as:

1. What are the processes and best practice we can learn from around the world, regarding vision and practice of implementing TMU?

2. What are the appropriate change management methods for this kind of change?

3. What are the specific characteristics in the Israeli system and in depth, in the Israeli universities? 
4. What are the varieties and divergences we need to take into account within the change process? (Universities in Israel divers in their size, character, history, structure and culture all in which we need to take into account)

5. What are the specific steps and mechanisms (roadmap) needed in order to achieve organizational (structural and cultural) change?

\subsection{Research Method}

The study firstly includes a broad literature review and analysis. Then we formulate interviews with key personnel in the higher education system and in universities. Key personnel are defined as people involved in decision-making processes related to the cultural change, as well as people in positions of authority who can participate in the process as a change agent or a change leader. As well as TTO's managers and personnel, people who play an important role in industry, governmental stakeholders and authorities. In addition to the interviews, other primary and secondary documents hade been reviewed: lists of members of various committees; summaries of debates and hearings; internal newsletters of the organizations; intra-net publications; public appeals; calls for proposals; university-wide advertisements; publications in professional journals and in the press; and published and unpublished reports. Criteria's data as mentioned for describing third mission level. Based on the outcome of the interviews, an more in -depth case study

\section{Global Higher Education System and the Israeli Academic System}

Educational organizations are qualitatively different from business or commercial organizations. Their management parameters are different, they operate differently, and frequently their organizational values and the criteria for judging the organization's success are also different. The educational organization is considered a "loosely coupled system." This term refers to a situation in which two occurrences share only a few common variables, or the variance between the occurrences pertains to less important variables. Therefore, their common variance is reduced, and the ability to predict one occurrence based on the other is limited (Weick, 1976).

In a loosely coupled system, the sub-systems and their operations are partially linked, yet each sub-system maintains its privacy and independent identity. The parts of the system are attached by a delimited relation of dependency and control.

Theses facts are pertinent also to the link between the organization and the environment. Pressures from the environment or demands for change are "shielded" and do not infiltrate as a parameter that requires the organization to take action. Loose coupling is a characteristic of the structure of academic institutions (Weick, 1976). Educational organizations are defined as having loose couplings between environment, technology, policy, coordination, and supervision. A consideration of the university's culture and structure must take into account not only the traditional university, but also the various models and structures which in recent years have developed into universities of a different nature. A distinction must be drawn between research institutions and colleges, private and government owned universities, and between the traditional and the entrepreneurial universities (Kirp, 2003; Heeger, 2000; Lueddeke, 1999). Nevertheless, despite the variety of universities and the distinctions among them, there are some characteristics that are valid for the majority of universities.

The university has been defined by investigators as an "organized anarchy" (Cohen \& others, 1986). In the university, where goals are neither unequivocal, conflicting, nor clear, standard theories of management and decision-making do not hold. The university's goals, though easily defined in universal terms by any person of knowledge, do not conform to the basic criteria for defining goals. Boyer (1990) claims that the historical, cultural, and structural characteristics of the university create the conditions that prevent it from initiating and establishing an organized and systematic mechanism for managing and assimilating change. At the same time, the university exists in a social and cultural environment that requires it to respond to frequent changes in market demands, budgetary shifts, and technological innovations (Wilms \& Zell, 2003; Bates, 1999).

In Israel, the universities have had to face changes. The demands made on the universities by the establishment that funds their scientific and cultural activities, for accountability and managerial leadership on the one hand, and the demands made by the market, technology, and the customers on the other hand are forcing the universities to abandon the ivory tower, where they had maintained an unchanged existence, and to adjust themselves to their environment. The Melz Report for Changing the University's Structure (2000) indicates that the current structure prohibits free flow of information among its units, limiting the possibility of introducing necessary changes and innovations. "The current structure of most academic institutions is characterized by loose coupling among its 
academic and functional units. The structure is noted for several essential weak points relating to the work patterns of its units, issues of authority and role allocation, and the reciprocal relations between these components.

A "top-down" strategy for handling organizational changes in the university is a major vehicle for managing change in higher education, where "most layers of management and knowledge employees are isolated from environmental demands and from the administration thanks to their tenured status and the important feature of "academic freedom," which provides the pretext for separate departments to reject the university administration's decisions. The "top-down" strategy has borne positive results in terms of change implementation and technology integration in teaching and management processes" (Wilms \& Zell, 2003).

\section{4. "Third Mission University" - Models and Definitions}

The literature offers a number of models for analyzing and implementing the "Third Mission University" and many terms and definitions for those activities:

"The Tried Research University"(Tadmor, 2003), "The Triple Helix University" or "The Entrepreneurial University" and "The future university". "Third stream activity" (Hatakenaka, 2005) or "Technology Transfer". Within a modern, knowledge driven economy, knowledge transfer (KT) is about transferring good ideas, research results and skills between universities, other research organizations, business and the wider community to enable innovative new products and services to be developed (TTO Leeds University homepage). "Knowledge transfer is the deliberate process of exchanging information from one part of the knowledge system useful to another part, often across sectors or disciplines" (NSF 2007). Others terminology refers to the "University-to-Industry" relationship, that is to the emerging need to commercialize research output in order to enhance economic progress and a country's competitiveness, through which the university rewards society for its financial support. Another definition talks about enhancing the economic and social impact of universities, help develop innovation and new technologies, help industry renewal and breakthrough (Hatakenaka, 2005). Universities play a key public role in development contributing commercial and progress in variety of issues and with in society and putting knowledge to use (Etzkowitz, 2002). There are a number of models of Third Mission University:

1. Individual-Institutional-Organizational (Phan \& Siegel, 2006).

2. Entrepreneurial University - productivity of TTO - New firm- environmental and networks of innovation. (Rothaermal, Agung and Jiang, 2006).

3. Instill economic impact as universities value. (Hatakenaka, 2005).

4. Five domains of organizational Policy and Practice (Jacobson, Butterill \& Goering, 2004).

5. The Singapore Model ( Wong, 2007)

\section{Change Management- Tools for Implementation}

The underlying assumption of this study is that there is no universal fit-for-all solution for implementing the TMU. We need to find the right way to meet the cultural differences and regional conditions to articulate a good-enough roadmap for implementing and managing the change. We believe using suitable change management strategy and specific measures to monitor the process; can help university progress towards the goal of implementing the "Third Mission University"

There are several models and methods of change management.

\section{Research Method and design}

The model of dynamic stability (Levin, 1952). According to this model, the main concepts in the process of change management are "unfreeze, change, and freeze". These terms were influenced by the perception of the organization as a balanced system that operates in an environment that is not always stable and can cause a shift in the organization's equilibrium. This model aims to bring the organization back to a balanced state. The change is considered a transitional period, at the end of which the organization's equilibrium will be re-established.

The problem-solving model (Nickols, 2004). This model considers change as the shift from the problem stage to the solution stage. Once a problem is encountered, it must be defined as critical. Then goals are set and multiple solutions are identified. This process must be carefully planned.

The model of interactive strategic planning (Nickols, 2004). This model proposes three stages in change management: discontent, a vision, and the first step towards change. First there is the emergence of discontent with the current situation. This is countered with a vision for the future, and then the first step for implementing this vision must be planned. 
The eight step model (Kotter, 1998). These steps include establishing a sense of urgency, creating leading coalitions, developing a vision and a strategy, clarifying the change and the vision, creating a strong foundation for action, creating successful experiences in the immediate future, assessing the change and defining additional changes, and finally, anchoring the new approaches within the organizational culture.

The model of organizational dynamic systems (Burke \& Litwin, 1992). This model distinguishes between transactional systems (which include an exchange) and transitional systems (which include a process of change). In a transactional system, its components create the climate necessary for change, whereas in a transitional system, the components are the very behaviors that need to be altered, as part of the organization's action for change management.

When a systematic change is planned, there is a crucial need for measurements to identify its base line from witch the change is taking place and to realize the distance from the desired target. "It is important to identify appropriate criteria and indicators for describing the technological transfer" (NSF, 2007.p.7). The technology transfer phenomenon is complex and so is the measurement process. We will repeatedly examine and double check the data that are available in this research for further validation.

1. Research output

Publications, conference proceedings, symposia, trade journals, web publications and networks.

2. Collaboration

Interactions, formal and informal, any kind of F2F of ICT interactions (Technology mediated), partnership (financed research, faculty consultancy)

3. Economic impact

Any activity that increases value - individual, organizational or regional (patents, disclosures, license and spin-offs)

4. Interdisciplinarity

5. Education and training

Classroom learning, learning by doing, know-how, graduate students, training programs.

6. Societal at al.

Any form of dialogue with public, dissemination of information, developing educational needs, identifying barriers and ethical issues.

\section{Conclusion}

Few research studies relate to the barriers for changes, as well as to individual changes. "There is no smooth path for any paradigm change" (Rothaermal, Agung and Jiang, 2006 p. 15, 17). The research mentions that "as the scope of an entrepreneurial university expands, the core of the system self-organizes in order to renew and transform its mission" (Rothaermal, Agung and Jiang, 2006, p.8) but does not give any indication as to the way to achieve these goals. Based on existing global best practices for implementing the "Third Mission University", using change management theory and tools, will provide rational and practical steps which a given university can follow and by which policy makers can steer the academic system.

As the "Third Mission University" is one of the main changes in the academic world, in addition and side by side to the traditional missions of education (teaching) and research (Rothaermal, Agung and Jiang, 2006) universities ought to have the adequate theory and practice to face the challenge in an organizational and systematic way.

\section{References}

Agrawal, A. (2001). University-to-Industry knowledge transfer: literature review and unanswered questions. International Journal of Management Review, 3, 285-302. Blackwell Publishers Ltd. Oxford. UK. http://dx.doi.org/10.1111/1468-2370.00069

Anand, N., Gardner, H.K., \& Morris, T. (2007). Knowledge-Based Innovation: Emergence and embedding of New Practice Areas in Management Consulting Firms. Academy of Management Journal, 50(2), 406-428. http://dx.doi.org/10.5465/AMJ.2007.24634457

Argote, L., \& Ingram, P. (2000, May). Knowledge Transfer: A Basis for Competitive Advantage in Firms. Organizational Behavior and Human Decision Processes, 82(1), 150-169.

AUTM U.S. Licensing Survey: FY 2004. 
Bercovitz, J., \& M, Feldman. (2006). Entrepreneurial Universities and Technology Transfer: A Conceptual Framework for Understanding Knowledge-Based Economic Development. Journal of Technology Transfer, 175-188. http://dx.doi.org/10.1007/s10961-005-5029-z

Bozeman, B. (2000). Technology transfer and public policy: a review of research and theory. Research Policy. Elsevier. http://dx.doi.org/10.1016/S0048-7333(99)00093-1

Bryen. L.L., Mason, E., \& Weiss.L.M. (2007). Harnessing the power of informal employee networks. The McKinsey Quarterly. McKinsey and Company. Retrieved from www.mckinseyquarterly.com.NY

Connecticut Technology Transfer and Commercialization Advisory Board of Governor's Competitiveness Council. (2004). Innovation Associates.

D’Este, P., \& P. Patel. (2005). Science and Technology Policy Research. University of Sussex.University - Industry linkages in the UK: what are the factors determining the variety of interactions with industry? Triple Helix5 Conference "The Capitalization of knowledge" Turin, Italy - 18 to 21 May 2005.

Entrepreneurial Studies in Higher Education. (2004). Vol. 24 No. 2. Higher Education in Europe UNESCO-CEPES European center for Higher Education.

Etzkowitz, H. (2002). MIT and the Rise of the Entrepreneurial University. London: Routledge. http://dx.doi.org/10.4324/9780203216675

Etzkowitz, H. (2002). The Rise of the Entrepreneurial University. Science Policy Institute. New York. http://dx.doi.org/10.4324/9780203216675

Etzkowitz, H.A., Webster, C., Gebhardt, \& B.R.C. Terra. (2000). The future of the university and the university of the future: evolution of ivory tower to entrepreneurial paradigm. Research Policy, Elsevier. http://dx.doi.org/10.1016/S0048-7333(99)00069-4

Etzkowitz. H, Mats, Benner, M., Guaranys, L., Maculan, A.M., \& Kneller. R. (2005). Managed Capitalism: Intellectual property and the rise of the entrepreneurial university in the U.S., Sweden, Brazil and Japan. Science Policy Institute, State University of New York at Purchase, N. Y., US, 13.

Jacobson, N., Dale, Butterill, \& Paula, Goering. (2004). Organizational Factors that Influence University-Based Researchers' Engagement in Knowledge Transfer Activities. Science Communication, 25(3), 246-259. SAGE Publications. http://dx.doi.org/10.1177/1075547003262038

Knowledge Transfer Activities in Connection with Nanoscale Science and Engineering. Final Report. (2007). National Science Foundation.

Levinthal, D.A., \& March, J. G. (1993). The Myopia of Learning. Strategic Management Journal, 14, 95-112. http://dx.doi.org/10.1002/smj.4250141009

March, J.G. (1991). Exploring and Exploitation in Organizational Learning. Organizational Science, 2(1). http://dx.doi.org/10.1287/orsc.2.1.71

Markman, G.D., P. H. Phan, D.B. Balkin, \& P.T. Gianiodis. (2005). Entrepreneurship and university-based technology transfer. Journal of Business Venturing, 241-263. Elsevier Inc. http://dx.doi.org/10.1016/j.jbusvent.2003.12.003

Meseri, O., \& Maital, S. (2001). A Survey Analysis of University-Technology Transfer in Israel: Evaluation of Projects and Determinants of Success. Journal of Technology Transfer, 26, 115-126. http://dx.doi.org/10.1023/A:1007844530539

Michael, L., Tushman, M.L., O’Reilly, C.A., Fenollosa, A., Kleinbaum, A.M., \& McGrath, D. (2007). Relevance and Rigor: Academy of Management Learning and Education. Special Issue: Challenges and Opportunities for Executive Education. Exaping Practice and Research.

Neo, B.S., \& Chen, G. (2007). Dynamic Governance. Embedding Culture, Capabilities and Change in Singapore. http://dx.doi.org/10.1142/9789812771919_0009

Parker, L.D. (2002). Critical Prespectives of Accounting, 13, 603-619. Elsevier Science Ltd. http://dx.doi.org/10.1006/cpac.2002.0561

Phan, P.H., \& D.S. Siegal. (2006). The Effectiveness of University Technology Transfer: Lessons Learned from Quantative and Qualitative Research in the U.S and U.K. Rensselaer Working Paper in Economics. NY. 
Renault, C.S. (2006). Academic Capitalism and University Incentives for Faculty Entrepreneurship. Journal of Technology Transfer, 31, 227-239. http://dx.doi.org/10.1007/s10961-005-6108-x

Rothaermel, F.T., S. D. Agung, \& L. Jiang. (2006). University Entrepreneurship: A Taxonomy of Literature. In D, S. Siegel, M, Wright and A, Lockett (Eds.), The Rise of Entrepreneurial Activity at Universities: Organizational and Social Implications. Industrial and Corporate Change.

Schulte, P. (2004). The entrepreneurial university: a strategy for institutional development. Higher Education in Europe, 29(2). http://dx.doi.org/10.1080/0379772042000234811

Tadmor, Z. (2003). The Golden Age of Scientific Technological Research University. The S. Neaman Institute of Advanced Studies in Science and Technology. Technion Israel Institute of Technology.

Tadmor, Z. (2003). The Triad Research University Model or a Post $20^{\text {th }}$ Century Research University Model. The S. Neaman Institute of Advance Studies in Science and Technology. Technion Israel Institute of Technology, 27.

The brains business. Mass higher education is forcing universities to become more diverse, more global and much more competitive, says Adrian Wooldridge. Sep 8th 2005, The Economist, print edition.

Vakkuri, J. (2004, September). Institutional Change of Universities as a Problem of Evolving Boundaries. Higher Education Policy, 17(3), 287-309. http://dx.doi.org/10.1057/palgrave.hep.8300056

Van de Van, A. H., \& Poole, M.S. (1995). Explaning development in Organizations. Academy of management Review, $20,3$.

Vestergaard, J. (2007). The Entrepreneurial University Revisited: Conflicts and the Importance of Role Separation. Social Epistemology, 21, 41-54. http://dx.doi.org/10.1080/02691720601125498

Whiteley, A., \& J, Whiteley. (2007). Core Values and Organizational Change: Theory and Practice. Curtin University of Technology, Australia.

Wong, P, K. (2007). Commercializing biomedical science in a rapidly changing "triple-helix" nexus: The experience of the National University of Singapore. Journal of Technology Transfer, 32(4), 367. http://dx.doi.org/10.1007/s10961-006-9020-0

Wong, P.K, Ho, Y.P., \& Singh, A. (2005). Towards an "Entrepreneurial University" Model to Support Knowledge-Based Economic Development: The Case of the National University of Singapore. Entrepreneurship Centre. National University of Singapore. 